\title{
Fuel additives production: ethyl-t-butyl ether, a case study
}

\author{
Vladimír Mikuš, Martina Ridzoňová, Pavol Steltenpohl \\ Department of Chemical and Environmental Engineering, \\ Faculty of Chemical and Food Technology, Slovak University of Technology in Bratislava, \\ Radlinského 9, 81237 Bratislava, Slovakia \\ pavol.steltenpohl@stuba.sk
}

\begin{abstract}
The students frequenting the program Chemical Engineering at the Department of Chemical and Environmental Engineering, Faculty of Chemical and Food Technology of the Slovak University of Technology in Bratislava are taught to be able to combine and develop their knowledge acquired in the area of chemical, energetic, environmental, and safety engineering. Prior to completing their study, they are obliged to develop a report regarding engineering, economic, and safety analysis of important chemical technology. This paper presents the most valuable outputs of the student's Technology project aimed on simulation and optimization of the fuel additives production technology. 2-Ethoxy-2-methylpropane (ethyl-t-butyl ether, ETBE) production based on liquid-phase etherification of 2-methylpropene with ethanol in the presence of heterogeneous catalyst was studied. Different patented technologies were investigated in terms of their profitability and safeness. The first technology was an isothermal reactor with the product separation via distillation (Kochar \& Marcell, 1981). The next ETBE production design assumed was a modification of the previous one; the product separation was carried out using liquid-phase extraction (Pucci et al., 1992). The last design considered in this study was a reactive distillation column with a pre-reactor (Bakshi et al., 1992). In all three technologies, etherification reaction was carried out using Amberlyst ion-exchange resin in its $\mathrm{H}^{+}$form as the catalyst. Selected ETBE production designs were simulated using Aspen+ program. Their profitability was compared on basis of the investment and operation costs assessment taking into account both the produced ETBE yield and purity. Further, basic safety analysis of all chosen technologies was performed in order to identify possible hazards. Finally, individual and social risk connected with the plant operation was computed. Taking into account these economic and safety criteria, the best alternative for ETBE production was the reactive distillation.
\end{abstract}

Keywords: ethyl-t-butyl ether production, heterogeneous catalysis, individual and social risk, investment and operational costs, product purity

\section{Introduction}

Gasoline and diesel are principally produced from crude oil that is classified as exhaustible fossil fuel. Worldwide, only a small part of the crude oil is used for production of other chemicals, oils, and bitumen, in comparison with the production of liquid fuels. In a view of limited world supplies of crude oil, alternative fuels for internal combustion engines were proposed. Among others, biofuels prepared from renewable sources seem to be very promising alternative. The most common substitute to gasoline is ethanol. Still, from various reasons the use of fossil fuels for propulsion engines prevails, although admixture of biocomponents to these fuels is set by legislation (EU Parliament, 2003; Čerňanský, 2008). Thus, it is expected that classical propulsion engines consuming gasoline and diesel will be substituted with modern technologies first within 20 to 40 years (Králik et al., 2000).

Quality and yield of gasoline and diesel in terms of treating crude oil were not equal over time. We can see an improvement of the fuel quality and a regress of an environmental impact of the fuel combustion. Ever stringent requirements are applied regarding the environmental protection, especially looking at the emissions of polycondensed hydrocarbons (i.e. carcinogens, mutagens, teratogens) nowadays (EU Parliament, 2003, 2009). This effect is related with the reduction of aromatics content in the gasoline, what is a target of EURO standards (EU Parliament, 2007; Králik et al., 2000). On the other hand, reduction of aromatics content in gasoline causes reduction of an octane number. Therefore, it is necessary to replace aromatics in the gasoline with others compounds possessing favorable octane number.

Alcohols and ethers are the most commonly used organic oxygenate additives to gasoline, because of their high octane number and due to the fact that these additives are produced from renewable sources. Blending relatively small percentages of oxygenated compounds with gasoline has the effect of reducing the volumetric energy content of the fuel while improving its anti-knock performance. Moreover, due to the lower volumetric energy 
content of gasoline leaner air-fuel mixture could be used in internal combustion engine, thus helping to reduce $\mathrm{CO}$ and $\mathrm{HC}$ emissions (Steltenpohl, 2011). Application of alcohols (especially methanol) as fuel additives is restricted due to their limited blending with hydrocarbons, toxicity, volatility, and price. Therefore, ethers seem to be more appropriate to be used as gasoline additives.

The first of ethers used in gasoline blending was 2-methoxy-2-methylpropane (methyl-t-butyl ether, MTBE). MTBE has been widely used since 1990s when some environmental regulations started to limit the aromatic content in gasoline (Yuan, 2006). Initially, MTBE was used at a low percentage as an octane number enhancer, and later was blended at higher concentration (10-15 mass \%) as oxygenate to meet the Glean Air Act requirements (Yuan, 2006; US EPA, 1990). Positive benefits of MTBE addition to gasoline (i.e. reduction of $\mathrm{CO}$ content in exhaust gases by about $25 \%$ ) were, however, outbalanced by direct and indirect impact of this additive on the environment (carcinogenic effects). MTBE is a persistent substance in soil and ground water, resulting from its molecular structure comprising an ether bond and a tertiary carbon group (Yuan, 2006; Králik et al., 2000). Although degradation of MTBE has been reported either under aerobic or anaerobic conditions, very low degradation rates were observed (Yuan, 2006). Increasing wave of dislike was imposed against the use of MTBE worldwide. Nowadays, application of MTBE is prohibited in the USA (Yuan, 2006).

The alternative to MTBE, in terms of availability and employing similar production concept, is 2-ethoxy-2methylpropane (ethyl-t-butyl ether, ETBE). ETBE is presented as a "green" alternative to MTBE assum- ing that it is produced from renewable source, bioethanol (Nagy, 2008; Čerňanský, 2008). Standards applied to assess the fuel quality determine the maximum content of additives in gasoline (Slovak Office of Standards, Metrology and Testing, 2013). At present, maximum content of ETBE in gasoline is 15 vol. \%; however, a consecutive increase of its content in gasoline up to $22 \mathrm{vol}$ \% is discussed. In the year 2009, production of ETBE was 2.59 million tons in the Europe (Mirzoyev \& Pushchyk, 2009). Basic properties of MTBE and ETBE are summarized in Table 1.

The aim of this case study is a design of technology for production of 4000 tons of ETBE per year. A part of this project is the simulation of three different technologies for production and consecutive separation of ETBE based on the patent information (Kochar \& Marcell, 1981; Pucci et al., 1992; Bakshi et al., 1992; Weber de Menezes \& Cataluña, 2008). The simulations were carried out using the Aspen+ software. Single alternatives are compared with each other in the terms of several parameters: purity of product, total investment costs, total operation costs, and also safeness assessed on basis of the individual and social risk of ETBE production. Based on these results, the best alternative for ETBE production is recommended.

\section{2-Methylpropene etherification with ethanol}

Minimization of costs in petrochemical industry is oriented on a complete utilization of crude oil. $\mathrm{C}_{4}$ fraction (containing hydrocarbons with four carbon atoms such as butane, 2-methylpropene, and 1-butene) is a by-product (a waste) formed

Tab. 1. Physical and chemical properties of MTBE and ETBE (Yuan, 2006).

\begin{tabular}{|c|c|c|}
\hline Property & MTBE & ETBE \\
\hline \multicolumn{3}{|l|}{ Molecular structure } \\
\hline Molecular formula & $\mathrm{CH}_{3} \mathrm{OC}\left(\mathrm{CH}_{3}\right)_{3}$ & $\mathrm{CH}_{3} \mathrm{CH}_{2} \mathrm{OC}\left(\mathrm{CH}_{3}\right)_{3}$ \\
\hline Octane number & 116 & 118 \\
\hline Molecular mass/(kg kmol $\left.{ }^{-1}\right)$ & 88 & 102 \\
\hline Normal boiling point $/{ }^{\circ} \mathrm{C}$ & 55.3 & 73.1 \\
\hline Oxygen content/mass \% & 18.2 & 15.7 \\
\hline Vapor pressure at $25^{\circ} \mathrm{C} / \mathrm{kPa}$ & 36.0 & 24.3 \\
\hline Water solubility/(mg L $\left.{ }^{-1}\right)$ & 42 & 23.7 \\
\hline Henry constant & 43.8 & 140 \\
\hline $\log K_{\mathrm{ow}}$ & 1.2 & 1.74 \\
\hline $\log K_{\mathrm{oc}}$ & 1.05 & 2.2 \\
\hline
\end{tabular}


during cracking of crude oil fractions. Compared to an energetic use (combustion), production of ethyl-t-butyl ether (ETBE), i.e. a product of high added value, from 2-methylpropene is much sophisticated use of this "waste". Production of ETBE from 2-methylpropene and ethanol is described by the following reaction

$$
\left(\mathrm{CH}_{3}\right)_{2} \mathrm{C}=\mathrm{CH}_{2}+\mathrm{C}_{2} \mathrm{H}_{5} \mathrm{OH} \rightleftarrows\left(\mathrm{CH}_{3}\right)_{3} \mathrm{COC}_{2} \mathrm{H}_{5}
$$

This chemical reaction is reversible, exothermic (heat of reaction in the liquid phase of about $-35 \mathrm{~kJ} \mathrm{~mol}^{-1}$ at $298 \mathrm{~K}$ ), and typically is carried out in liquid phase in the presence of heterogeneous acidic catalyst (Françoisse \& Thyrion, 1991).

Mechanism of the liquid-phase etherification of 2-methylpropene with ethanol depends on the reactants' concentration, especially on the ethanol concentration in the reaction mixture. Françoisse and Thyrion (1991) discussed two mechanisms of 2-methylpropene etherification with ethanol. At the large excess of ethanol, the general reaction (Eq. (1)) could be split into two partial reactions:

$$
\begin{gathered}
\mathrm{M}-\mathrm{SO}_{3}^{-} \mathrm{H}^{+}+\mathrm{C}_{2} \mathrm{H}_{5} \mathrm{OH} \underset{\pi_{2}}{\stackrel{\vec{k}_{2}}{\rightleftarrows}} \\
\stackrel{\vec{k}_{2}}{\rightleftarrows} \mathrm{M}-\mathrm{SO}_{3}^{-} \ldots \mathrm{C}_{2} \mathrm{H}_{5} \mathrm{OH}_{2}^{+} \\
\mathrm{M}-\mathrm{SO}_{3}^{-} \ldots \mathrm{C}_{2} \mathrm{H}_{5} \mathrm{OH}_{2}^{+}+\left(\mathrm{CH}_{3}\right)_{2} \mathrm{C}=\mathrm{CH}_{2} \underset{\pi_{3}}{\stackrel{\vec{k}_{3}}{\rightleftarrows}} \\
\underset{\pi_{3}}{\rightleftarrows} \mathrm{M}-\mathrm{SO}_{3}^{-} \mathrm{H}^{+}+\left(\mathrm{CH}_{3}\right)_{3} \mathrm{COC}_{2} \mathrm{H}_{5}
\end{gathered}
$$

where $\vec{k}_{2}, \overleftarrow{k}_{2}$ and $\vec{k}_{3}, \overleftarrow{k}_{3}$ are the forward and backward reaction rate constants for Eqs. (2) and (3), respectively.

Sulfonic group, $\mathrm{SO}_{3} \mathrm{H}$, is strongly chemically bound to anhydrous resin applied on apolar inert solvents. In the presence of some polar substance (e.g. water, alcohols, etc.), $\mathrm{O}-\mathrm{H}$ bond of the $\mathrm{SO}_{3} \mathrm{H}$ group is disrupted and a new hydrogen bond is formed with this polar substance (Eq. (2)). The protonational step (Eq. (2)) is necessary for the completing of etherification reaction. Results of studies indicate that, in the case of ethanol excess in the reaction mixture, the rate-limiting step of 2-methylpropene etherification is Eq. (3) (Françoisse \& Thyrion, 1991).

In the case of low ethanol concentration, molecule that undergoes protonation is 2-methylpropene. This is also the rate-limiting step of 2-methylpropene etherification reaction (Eq. (1)), which is a combination of the following partial reactions:

$$
\begin{gathered}
\mathrm{M} \longrightarrow \mathrm{SO}_{3}^{-} \mathrm{H}^{+}+\left(\mathrm{CH}_{3}\right)_{2} \mathrm{C}=\mathrm{CH}_{2} \stackrel{\vec{k}_{4}}{\rightleftarrows} \\
\stackrel{\frac{\vec{k}_{4}}{\varkappa_{4}}}{\rightleftarrows} \mathrm{M}-\mathrm{SO}_{3}^{-} \ldots \mathrm{C}_{4} \mathrm{H}_{9}^{+} \\
\mathrm{M}-\mathrm{SO}_{3}^{-} \ldots \mathrm{C}_{4} \mathrm{H}_{9}^{+}+\mathrm{C}_{2} \mathrm{H}_{5} \mathrm{OH} \underset{\hbar_{5}}{\stackrel{\vec{k}_{5}}{\rightleftarrows}} \\
\stackrel{\overrightarrow{k_{5}}}{\rightleftarrows} \mathrm{M}-\mathrm{SO}_{3}^{-} \mathrm{H}^{+}+\left(\mathrm{CH}_{3}\right)_{3} \mathrm{COC}_{2} \mathrm{H}_{5}
\end{gathered}
$$

where $\vec{k}_{4}, \overleftarrow{k}_{4}$ and $\vec{k}_{5}, \overleftarrow{k}_{5}$ are, respectively, the forward and backward reaction rate constants for Eqs. (4) and (5).

\section{Factors influencing equilibrium of etherification reaction}

2-Methylpropene reacts with ethanol following to Eq. (1) in the molar ratio of $1: 1$. As the reaction is reversible, according to the Le Chatelier's principle, the excess of one of the reactants (consecutive addition of this reactant) displaces the equilibrium towards the product formation. Equilibrium of reaction can also be displaced by separating the product from the reaction mixture.

Taking into account that the synthesis of ETBE by etherification of 2-methylpropene with ethanol is an exothermic reaction, 2-methylpropene conversion to ETBE is favored by lower temperatures. However, optimum operation temperature should be found, as lower temperatures cause decrease of the overall reaction rate. For the ETBE production from 2-methylpropene and ethanol the optimum temperature within $40-70{ }^{\circ} \mathrm{C}$ was found (Weber de Menezes \& Cataluña, 2008).

Influence of pressure on the etherification reaction equilibrium is negligible as the reaction is carried out in the liquid phase. Thus, the working pressure should fit the reaction temperature, i.e. should be fixed within $1 \mathrm{MPa}$ and $2 \mathrm{MPa}$ (reaction mixture should be a liquid) (Weber de Menezes \& Cataluña, 2008).

Inerts in the reacting system do not displace equilibrium of this reaction. Hydrocarbons in the $\mathrm{C}_{4}$ stream (butane, 1-butene) increase quantity of the manipulated material, thus increasing the separation equipment dimensions. On the other hand, the presence of water from aqueous ethanol solution causes that competing reaction (2-methylpropene hydration) could proceed diminishing the ETBE yield.

Catalyst does not affect reaction equilibrium, but it exercises a desired influence on the reaction velocity. Process of ETBE production is catalysed by acidic heterogeneous catalysts, e.g. AMBERLYST 15 and LEWATIT K2631 (Kochar \& Marcell, 1981; Pucci et al., 1992; Bakshi et al., 1992; Weber de Menezes \& Cataluña, 2008; Nagy, 2008).

\section{Side reactions}

In case that large excess of 2-methylpropene in the liquid-phase etherification is used, 2-methylpropene dimerization (Eq. (6)) on the acidic catalyst could not be discarded. However, reaction conditions favorable for 2-methylpropene dimerization are seldom met and, moreover, kinetics of this reaction was to our knowledge not published. Therefore, we ignored it in this study 


$$
\begin{gathered}
2\left(\mathrm{CH}_{3}\right)_{2} \mathrm{C}=\mathrm{CH}_{2} \rightleftarrows \\
\rightleftarrows\left(\mathrm{CH}_{3}\right)_{3} \mathrm{CHCH}_{2} \mathrm{CH}=\mathrm{C}\left(\mathrm{CH}_{3}\right)_{2}
\end{gathered}
$$

Other components of the $\mathrm{C}_{4}$ fractions are less reactive under chosen reaction conditions. Consequently, any side reactions concerning these components were not taken into account.

For the 2-methylpropene etherification the use of either absolute ethanol or its aqueous solutions with low water content (minimum ethanol content of 90 mole \%) was suggested (Françoisse \& Thyrion, 1991). The presence of higher amount of water shows adverse effects on the principal reaction. Firstly, water could compete with ethanol in the reaction with 2-methylpropene, thus diminishing the ETBE yield. Moreover, washing out of the catalyst sulfonic groups by water reduces the catalyst activity (Françoisse \& Thyrion, 1991).

Water easily reacts with sulfonate group protons. This is the first step leading to the side product, tertiary butanol ( $t$-butanol, TBA), formation in the liquid phase. This side product does not influence negatively the subsequent reaction mixture separation. Both ETBE and TBA exhibit high octane number; therefore, the TBA admixture in gasoline additives is tolerated (Kochar \& Marcell, 1981).

Production of TBA is described by the following chemical reaction

$$
\left(\mathrm{CH}_{3}\right)_{2} \mathrm{C}=\mathrm{CH}_{2}+\mathrm{H}_{2} \mathrm{O} \rightleftarrows\left(\mathrm{CH}_{3}\right)_{2} \mathrm{CHCH}_{2} \mathrm{OH}
$$

\section{Patented technologies for ETBE production and separation}

In the patent literature regarding the ETBE production, two principal sections are distinguished, namely reaction and separation section. The reaction section is common for all found technologies; it consists of an isothermal fixed bed of catalyst placed in the reactor, in which a liquid-phase reaction is carried out (Eq. (1)). One should account also on the side reaction, TBA formation (Eq. (7)). In the reactor, operating conditions (i.e. temperature, pressure) favorable for the equilibrium displacement toward product, are maintained.

The separation section differs for individual ETBE production technologies. Product is separated from the reaction mixture either by distillation, extraction, or the reaction and separation sections are combined to form reactive distillation system (Kochar \& Marcell, 1981; Pucci et al., 1992; Bakshi et al., 1992; Weber de Menezes \& Cataluña, 2008).

\section{ETBE production in isothermal reactor with the product separation by distillation}

$\mathrm{C}_{4}$ fraction from cracking the crude oil is fed in the reactor together with an excess of ethanol solution (purity of ethanol better than 95 mole \%). Operating conditions applied practically avoid the dimerization reaction. Reaction mixture leaving reactor contains ETBE, TBA, ethanol, unreacted 2-methylpropene, and inerts from $\mathrm{C}_{4}$ fraction. Separation section of this technology is composed of two distillation columns (Fig. 1). In the first column, the remains of the original $\mathrm{C}_{4}$ fraction (2-methylpropene, butane, 1-butene) are separated in the form of distillate. Bottom product from the first column is a feed for the second one where ETBE and TBA are separated as the bottom product (Kochar \& Marcell, 1981).

\section{ETBE production in isothermal reactor with the product separation by extraction}

Production of ETBE is carried out according to the flow chart shown in Fig. 2. In the fix bed reactor, aqueous ethanol in excess reacts with 2-methylpropene from $\mathrm{C}_{4}$ fraction. Reaction mixture, besides the

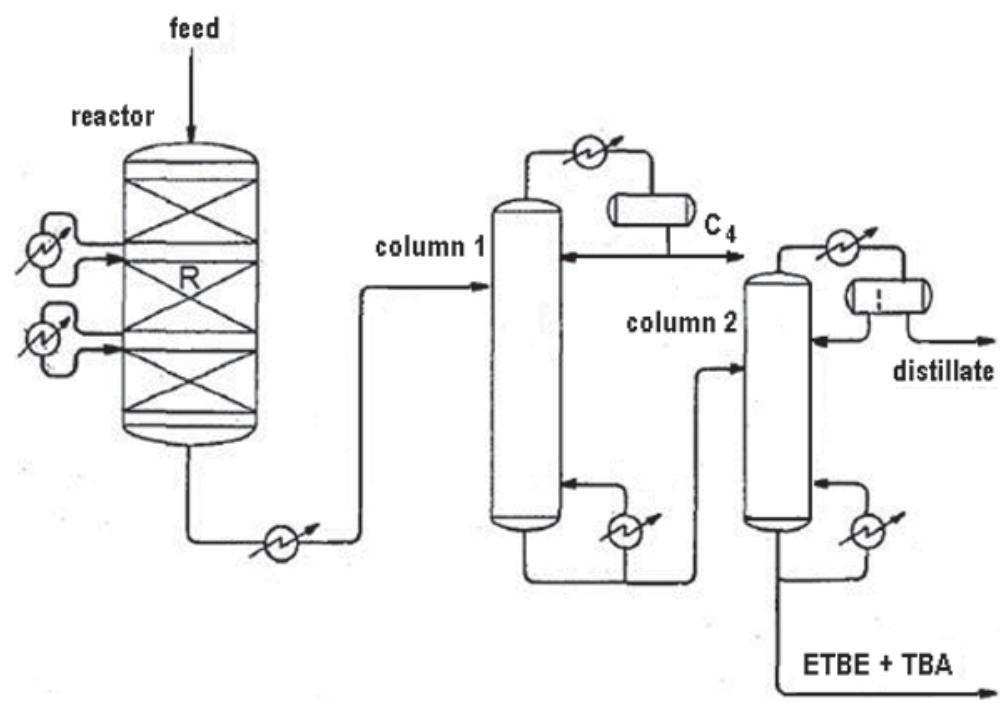

Fig. 1. Scheme of the patented technology for ETBE production in an isothermal reactor with the product separation by distillation (Kochar \& Marcell, 1981). 


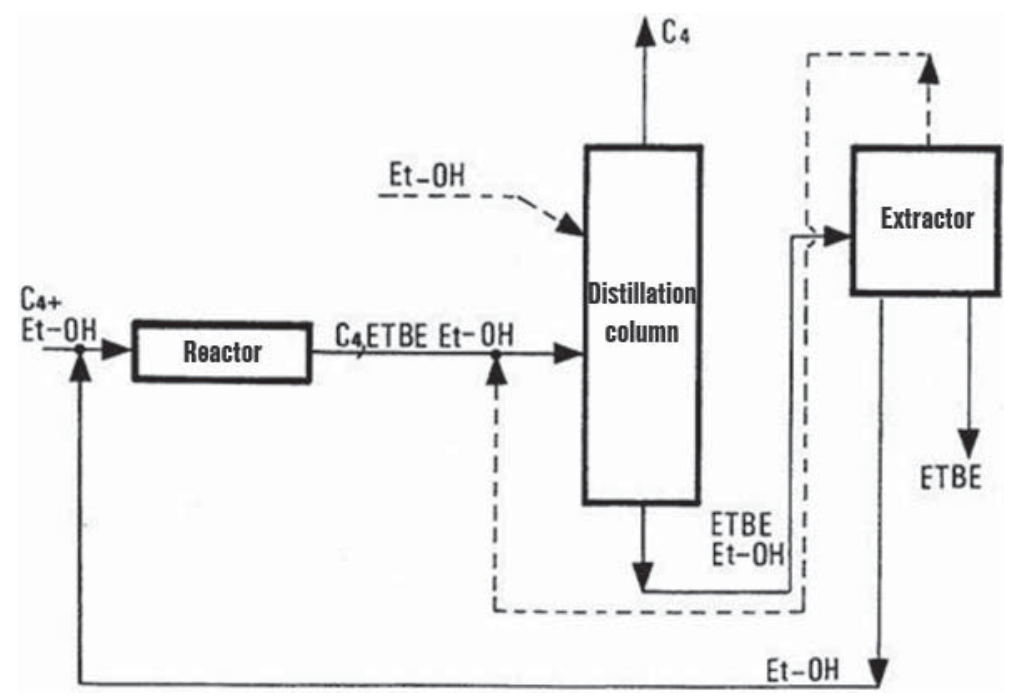

Fig. 2. Scheme of the patented technology for ETBE production in an isothermal reactor with the product separation by extraction (Pucci et al., 1992).

desired product, ETBE, contains ethanol as well as butane and 1-butene (inerts). Inerts are separated in a distillation column. Bottom product from this column is a mixture of ETBE with up 10-30 mass \% of ethanol. Ethanol contained in this mixture is removed by liquid-phase extraction process. Extractor is operated at $50{ }^{\circ} \mathrm{C}$ to $70{ }^{\circ} \mathrm{C}$ and the working pressure is $0.1-0.2 \mathrm{MPa}$. As an extraction solvent in the extractor column water is used. Raffinate from the extractor includes practically total amount of ETBE produced together with a small portion of water. Extract is a mixture of ethanol and water, with traces of ETBE (Pucci et al., 1992).

\section{ETBE production in a straight pass reactor} combined with a catalytic distillation column reactor Process includes reaction of 2-methylpropene with ethanol in a straight pass reactor for the ETBE production, from which the reaction mixture containing unreacted 2-methylpropene and ethanol together with ETBE and inerts is transferred to a catalytic distillation column reactor to complete the reaction (Fig. 3). This novel type of equipment combines chemical reactor with separation unit. Simultaneous chemical (catalyzed) reaction and product removal allows obtaining higher conversion of feed components by shifting the equilibrium towards desired products.

Reactor as well as reactive zone of the distillation column involves heterogeneous catalyst placed in a fixed bed. Mixture of $\mathrm{C}_{4}$ hydrocarbons blended with liquid phase from the reactive zone of distillation column enters the straight pass reactor, where around $85 \%$ of 2-methylpropene is converted to ETBE. Reaction mixture from the reactor is fed to the distillation column below the reactive zone.
Here, ETBE is separated as the bottom product. Volatile components of the reaction mixture including 2-methylpropene enter the reactive zone of the distillation column. In the reaction zone, remains of 2-methylpropene react with ethanol. Ethanol stream containing small amount of water is fed to the column above the reactive zone. Water together with inerts (butane and 1-butene) leave the distillation column as distillate. Temperature in the column is maintained at the boiling point $\left(10-100^{\circ} \mathrm{C}\right)$; its actual value depends on the mixture composition as well as on the operating pressure in the column (0.3-1.14 MPa). Equilibrium of the 2-methylpropene etherification reaction is displaced towards the product formation due to the continuous product removal allowing to obtain nearly $100 \%$ conversion of 2-methylpropene (Bakshi et al., 1992; Pucci et al., 1992).

\section{Simulation of ETBE production, economy, and safety}

Beside the reactor design, other important issues in chemical technology are the product separation and purification, economic analysis, and risk assessment.

\section{ETBE production and separation modeling}

Selected technologies of ETBE production were modeled using the Aspen+ simulation engine. According to patent literature (Kochar \& Marcell, 1981; Pucci et al., 1992; Bakshi et al., 1992; Weber de Menezes \& Cataluña, 2008), distillation and extraction were applied for the product separation from the reaction mixture. Every design simulation requires setting of thermodynamic model for the phase equilibrium description. 


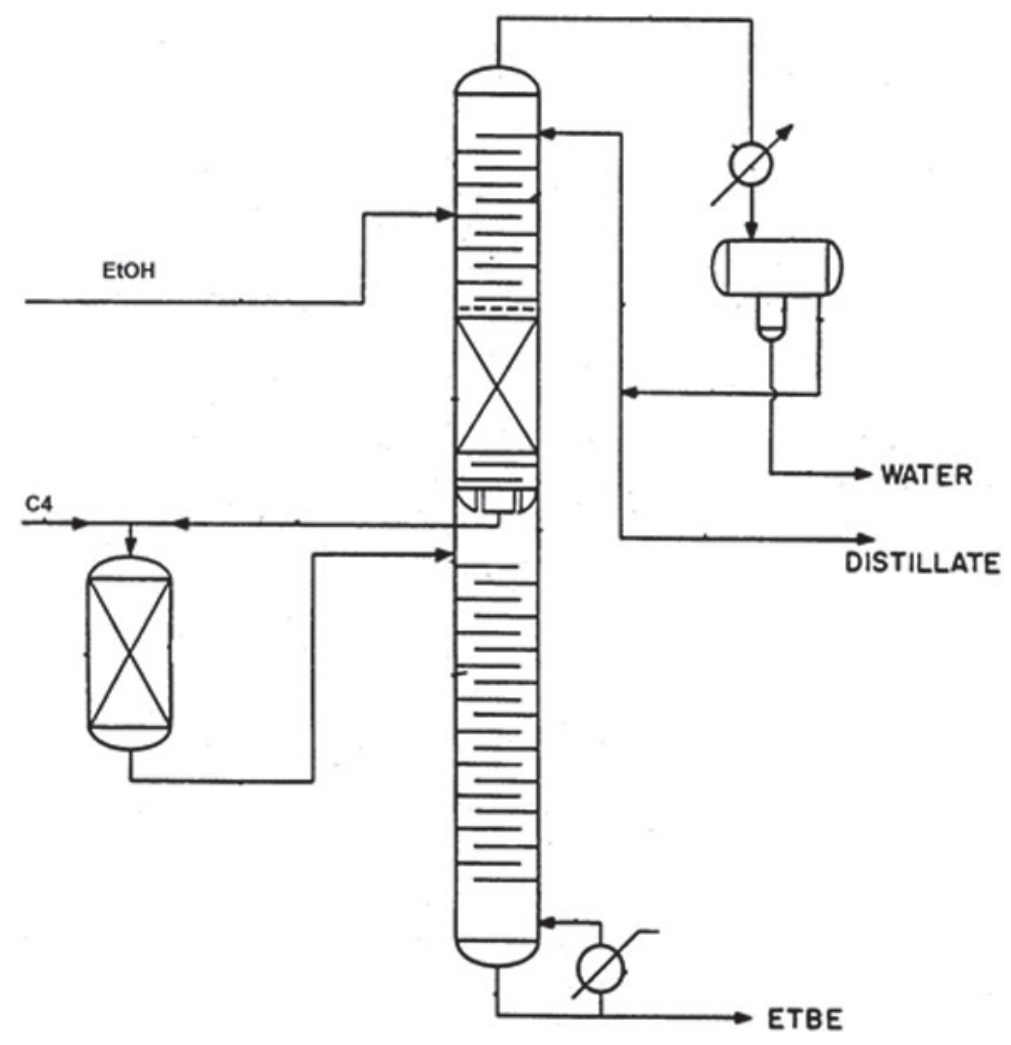

Fig. 3. Scheme of patented technology for ETBE production in straight pass reactor combined with a catalytic distillation column reactor (Bakshi et al., 1992; Pucci et al., 1992).

In the simulations it was used equilibrium reactor type as black box without application of kinetic parameters for general reaction (Eq. (1)) and side reaction (Eq. (7)). Simulation schemes do not account on circulation pumps; only pumps used to increase pressure of streams entering some equipment are considered. For some schemes a throttle valve was used for decreasing the pressure of manipulated stream.

For the purpose of the distillation column modeling, ideal behavior of the vapor and real behavior of the liquid phases was considered. Then, the vapor-liquid equilibrium could be described by the modified Raoult's law

$$
P y_{i}=P_{i}^{*} x_{i} y_{i}
$$

where $P$ represents system total pressure, $x_{i}$ and $y_{i}$ are the mole fractions of the component $i$ in the liquid and vapor phases, respectively, $\gamma_{i}$ its liquidphase activity coefficient, and $P_{i}^{*}$ stands for saturated vapor pressure of the pure component $i$. The values of saturated vapor pressure were calculated using the Antoine equation

$$
P_{i}^{*}=\exp \left[A+B / T+C \ln T+D T^{E}\right]
$$

where $A, B, C, D, E$ are empirical component-specific constants, $P_{i}^{*} / \mathrm{Pa}$ is the saturated vapor pressure, and $T / \mathrm{K}$ is temperature (Table 2 ).

Species which have limited mutual solubility in the liquid phase exhibit positive deviation from the Raoult's law. The quantitative measure of non-ideality of liquid mixtures is activity coefficient, $\gamma$, which is a function of the liquid-phase composition and

Tab. 2. Parameters of the Antoine equation.

\begin{tabular}{lccccc}
\hline Component & A & B & C & D & E \\
\hline 1-Butene & 51.836 & -4019.2 & -4.5229 & $4.8837 \times 10^{-17}$ & 6 \\
Butane & 66.343 & -4363.2 & -7.0460 & $9.4651 \times 10^{-6}$ & 2 \\
2-Methylpropene & 78.010 & -4634.1 & -8.9575 & $1.3413 \times 10^{-5}$ & 2 \\
Ethanol & 73.304 & -7122.3 & -7.1424 & $2.8853 \times 10^{-6}$ & 2 \\
Water & 73.649 & -7258.2 & -7.3037 & $4.1653 \times 10^{-6}$ & 2 \\
ETBE & 64.188 & -5820.2 & -6.1343 & $2.1405 \times 10^{-17}$ & 6 \\
TBA & 172.270 & -11589.0 & -22.1130 & $1.3770 \times 10^{-5}$ & 2 \\
\hline
\end{tabular}


temperature. In the case of extraction, liquid-liquid equilibrium is described by the isoactivity criterion

$$
a_{i}{ }^{1}=a_{i}{ }^{2}, y_{i}{ }^{1} x_{i}{ }^{1}=y_{i}{ }^{2} x_{i}{ }^{2}
$$

where $a_{i}$ is activity of the component $i$ in the equilibrium liquid phase $j$.

For the prediction of vapour-liquid and also liquid-liquid equilibrium of the system composed of ETBE, ethanol, water, $t$-butanol, and $\mathrm{C}_{4}$ fraction, the NRTL or UNIQUAG excess Gibbs energy models are recommended.

In this study, the Non-Random Two-Liquid (NRTL) model was chosen. Activity coefficients of a $K$-component system are calculated according to the equation

$$
\begin{gathered}
\ln \gamma_{i}=\frac{\sum_{j=1}^{K} \tau_{j i} G_{j i} x_{j}}{\sum_{l=1}^{K} G_{l i} x_{l}}+ \\
+\sum_{j=1}^{K} \frac{G_{i j} x_{j}}{\sum_{l=1}^{K} G_{l j} x_{l}}\left(\begin{array}{c}
\sum_{i j}^{K}-\frac{\tau_{n=1} G_{n j} x_{n}}{\sum_{l=1}^{K} G_{l j} x_{l}} \\
i=1,2, \ldots, K
\end{array}\right)
\end{gathered}
$$

where the model parameters $\tau_{i j}$ and $G_{i j}$ are defined as follows

$$
\begin{gathered}
\tau_{i j}=\frac{\left(g_{i j}-g_{j j}\right)}{R T}, G_{i j}=\exp \left(-\alpha_{i j} \tau_{i j}\right) \\
i, j=1,2, \ldots, K \quad i \neq j
\end{gathered}
$$

being $\left(g_{i j}-g_{j j}\right)$ and $\left(g_{j i}-g_{i i}\right)$ the interaction parameters between the molecules $i$ and $j, R$ general gas constant, and $\alpha_{i j}$ non-randomness model parameter (Table 3).

\section{Calculation of investment and operation costs}

Calculations of investment costs are based on the criterion equations. The f.o.b. purchase costs of selected chemical equipment are given in literature (Seider et al., 2008). In this case study only the main operating costs, i.e. the costs of raw materials and power media, were taken into account. It was chosen 8160 hours yearly fond of working time for the economic calculations. Table 4 summarizes costs of raw materials and power working media. Total investment capital was calculated by Woods index method (Mierka, 2010).

\begin{tabular}{|c|c|c|c|}
\hline Binary & $\left(g_{i j}-g_{j j}\right) /\left(\mathrm{cal} \mathrm{mol}^{-1}\right)$ & $\left(g_{j i}-g_{i i}\right) /\left(\mathrm{cal} \mathrm{mol}^{-1}\right)$ & $\alpha_{i j}$ \\
\hline 1-Butene-butane & 174.6980 & -138.7929 & 0.3021 \\
\hline 1-Butene-2-methylpropene & -93.2454 & 107.5264 & 0.3000 \\
\hline 1-Butene-ethanol & 595.5305 & 164.5723 & 0.3000 \\
\hline 1-Butene-water & 795.8131 & 1629.5605 & 0.3000 \\
\hline 1-Butene-ETBE & 226.3733 & -177.8856 & 0.3000 \\
\hline 1-Butene-TBA & 630.8417 & -48.1351 & 0.3000 \\
\hline Butane-2-methylpropene & -27.3395 & 50.0846 & 0.3000 \\
\hline Butane-ethanol & 926.1213 & 90.9830 & 0.3000 \\
\hline Butane-water & 1916.9819 & 1763.9619 & 0.3000 \\
\hline Butane-ETBE & 230.9685 & -167.8045 & 0.3000 \\
\hline Butane-TBA & 950.9944 & -89.7060 & 0.3000 \\
\hline 2-Methylpropene-ethanol & 623.5810 & 141.9632 & 0.3000 \\
\hline 2-Methylpropene-water & 830.0253 & 1587.9985 & 0.3000 \\
\hline 2-Methylpropene-ETBE & 219.7340 & -172.5915 & 0.3000 \\
\hline 2-Methylpropene-ТВA & 658.6645 & -62.8228 & 0.3000 \\
\hline Ethanol-water & $246.1800-0.8009 T$ & $-586.0809+3.4578 T$ & 0.3000 \\
\hline Ethanol-ETBE & 187.1040 & 344.4813 & 0.3000 \\
\hline Ethanol-TBA & 191.9405 & -205.5622 & 0.3000 \\
\hline Water-ETBE & 1990.4906 & 261.4153 & 0.3000 \\
\hline Water-TBA & $-1372.3835+7.0893 T$ & $203.4185-0.6868 T$ & 0.3000 \\
\hline ETBE-TBA & 390.3477 & 11.1240 & 0.3000 \\
\hline
\end{tabular}

\section{Safety analysis}

Operation of any chemical technology is accompanied by different types of hazards that correspond to

Tab. 3. Values of the NRTL parameters for the reaction mixture components obtained from the Aspen+ simulation program (UNIFAC predicted). 
Tab. 4. Raw materials, catalyst, and media costs.

\begin{tabular}{lcc}
\hline Material/medium & Price & Source \\
\hline Ethanol (96 mole \%) & $11.7 €$ per kmol & Al-Arfaj and Luyben (2002) \\
$\mathrm{C}_{4}$ fraction from cracking the crude oil & $6.4 €$ per kmol & Al-Arfaj and Luyben (2002) \\
Catalyst - Amberlyst 15 & $6.0 €$ per kg & Al-Arfaj and Luyben (2002) \\
Cooling water & $1 €$ per $\mathrm{m}^{3}$ & Mierka (2012) \\
Heating saturated steam & $10 €$ per GJ & Mierka (2012) \\
Electric power & $100 €$ per MWh & Mierka (2012) \\
Water for extraction & $100 €$ per $\mathrm{m}^{3}$ & Mierka (2012) \\
\hline
\end{tabular}

properties of materials used in the technology and handling of these materials. Typically, substances used in chemical technology are flammable, reactive, and toxic. In order to prevent consequences of the possible accidents, the risk assessment for the production line environment and area surrounding the installed technology must be carried out prior to its installation.

In this study, the risk identification was carried out using indexed Dow method. This method is based on the evaluation of 2 indices: Fire-explosive index and Index of toxicity. Fire and explosion index (FEI) quantifies the risk according to the physical and chemical properties of substances and technical design of the designed/employed technology. Index of toxicity (IT) is used to quantify biological risk of toxic substances (Jelemenský et al., 2012).

\section{Fire and explosion index (FEI)}

In order to evaluate FEI, material factor, common process factor, and special process factor should be computed. Material factor (MF) serves as a scale of energetic potential generated by fire or explosion of substances inhered in a technology. MF is calculated from the heat of combustion of a substance at $298 \mathrm{~K}$ (Jelemenský et al., 2012). To the overall value of common process factor $\left(\mathrm{F}_{1}\right)$ contribute six process characteristics, namely the presence of exothermic chemical reaction, presence of endothermic chemical reaction, manipulation and transport of material(s), presence of processes occurring in a closed space, input, and the presence of safety plant and drainage. Special process factor $\left(\mathrm{F}_{2}\right)$ is defined by eleven special characteristic of the process. Details on the special process factor calculation could be found e.g. in Jelemenský et al. (2012).

Fire and explosion index is then evaluated by Eq. (13):

$$
\mathrm{FEI}=\mathrm{MFF}_{1} \mathrm{~F}_{2}
$$

FEI is used to classify the fire and explosion risk of the operation of investigated chemical technology. Table 5 summarizes fire and explosion risk levels according to FEI value (Jelemenský et al., 2012).
Tab. 5. Levels of the risk of fire or explosion and the biological risk according to calculated values of Fire and explosion index and Index of toxicity, respectively.

\begin{tabular}{ccc}
\hline Risk level & FEI & IT \\
\hline Low & $0-30$ & $<2$ \\
Light & $30-60$ & $2-4$ \\
Medium & $60-95$ & $4-6$ \\
High & $95-125$ & $6-8$ \\
Very high & $125-155$ & $8-10$ \\
Extremely high & $>155$ & $>10$ \\
\hline
\end{tabular}

\section{Index of toxicity (IT)}

Index of toxicity (IT) describes the scale of biological risk of toxic substances used in the technology taking into account design of the production line. Both common and special material factors used in FEI calculation contribute to the value of the index of toxicity (IT). Toxicity of substance is defined by two toxicity factors. The first factor of toxicity, $\mathrm{T}_{1}$, is a measure of the substance total toxicity according to its impact on humans not distinguishing whether the substance enters the human body or not. It is evaluated from the coefficient of toxicity from the NFPA diamond (Jelemenský et al., 2012).

The second factor of toxicity, $\mathrm{T}_{2}$, corrects the value of the Index of toxicity for substances that by inhalation increase their toxic effect on humans. Factor $\mathrm{T}_{2}$ is evaluated based on the NPEL data (Jelemenský et al., 2012).

Then, the value of the index of toxicity (IT) is evaluated from Eq. (14):

$$
\mathrm{IT}=\left(\mathrm{T}_{1}+\mathrm{T}_{2}\right)\left(\mathrm{F}_{1}+\mathrm{F}_{2}-1\right) / 100
$$

In Table 5 classification of the biological risk according to value of IT is presented.

\section{Individual a social risk}

Risk of the technology operation can be classified into individual and social. Both types of risk can be evaluated from the same initial combination of haz- 
ard situations and expected results. Individual and social risks are instrumenting for comparison some simulation each other. Individual risk is a probability that some person will be injured during some time span (most frequently one year). It depends on the distance of a person from the source of hazard (Jelemenský et al., 2012).

Social risk is a probability that more people will die at the same time as a consequence of accident. This calculation of social risk includes also dispersion of people in the actual space and the influence of meteorological conditions (Jelemenský et al., 2011).

\section{Results and discussion}

In order to get comparable simulation results for different patented technologies for ETBE production, the same composition of feed stream of raw materials and the same reaction conditions were considered. Composition of feed streams as well as their temperature and pressure are given in Table 6 . Isothermal catalytic reactor was operated at the temperature of $40{ }^{\circ} \mathrm{C}$ and the pressure of $2 \mathrm{MPa}$. These conditions were chosen according to section Factors influencing equilibrium of etherification reaction and recommendation in the patent literature (Kochar \& Marcell, 1981; Pucci et al., 1992; Bakshi et al., 1992; Weber de Menezes \& Cataluña,
2008). Simulations were carried out in the Aspen+ code.

\section{ETBE production in isothermal reactor with the product separation by distillation}

In Fig. 4 the flow chart of the ETBE production line is presented according to data by Kochar and Marcell (1981). Heterogeneously catalyzed reaction is carried out in an isothermal reactor. Then, the reaction mixture enters the system of two distillation columns that are used for the mixture components separation. Calculated mass flows and composition of individual streams are presented in Table 7.

In this case study, total investment capital was calculated by Woods index method (Mierka, 2010). However, only the main operating costs regarding the raw materials and power media were calculated. The results of investment and selected operation costs are summarized in Table 8.

\section{ETBE production in isothermal reactor with the product separation by extraction}

Similarly to the first ETBE production technology, flow sheet in Aspen+ was developed as shown in Fig. 5. Based on this scheme, the steady state simulation was conducted and the results obtained are given in Table 9. Evaluated investment and operation (selected) costs are shown in Table 10.

Tab. 6. Feed streams composition.

\begin{tabular}{cccc}
\hline & $\mathbf{C}_{\mathbf{4}}$ fraction & & Aqueous ethanol solution \\
\hline Component & Content/mole $\%$ & Component & Content/mole $\%$ \\
\hline 1-Butene & 45 & Ethanol & \\
Butane & 10 & Water & \\
2-Methylpropene & 45 & Pressure $/ \mathrm{MPa}$ & 0.1 \\
Pressure $/ \mathrm{MPa}$ & 0.3 & Temperature $/{ }^{\circ} \mathrm{C}$ & 20 \\
\hline
\end{tabular}

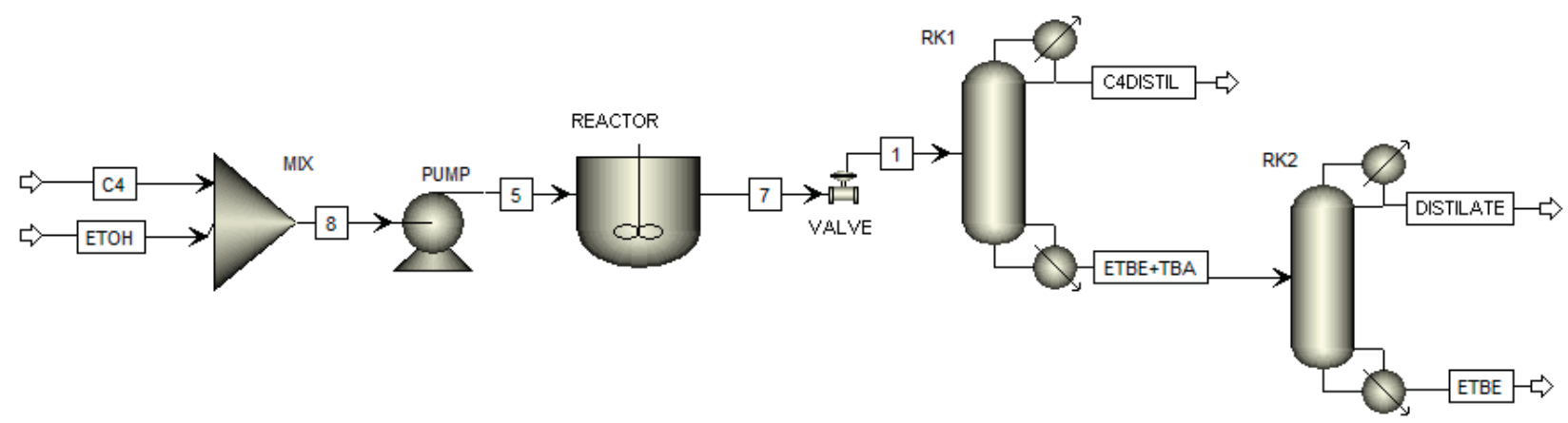

Fig. 4. Scheme of the ETBE production with the product separation by distillation. 
Tab. 7. Material flows for the simulation of ETBE production technology with the product separation by distillation.

\begin{tabular}{|c|c|c|c|c|c|}
\hline Stream & 7 & C4DISTIL & ETBE + TBA & DISTILATE & ETBE \\
\hline Mass flow/ $\left(\mathrm{kg} \mathrm{h}^{-1}\right)$ & 992.9 & 383.8 & 539.1 & 50.1 & 489.0 \\
\hline Temperature/ ${ }^{\circ} \mathrm{C}$ & 40 & 13 & 85 & 51.8 & 91.1 \\
\hline Pressure/MPa & 2.0 & 0.2 & 0.2 & 0.2 & 0.2 \\
\hline Component & \multicolumn{5}{|c|}{ Content/mass \% } \\
\hline 1-Butene & 32.8 & 78.0 & 0.7 & 6.8 & - \\
\hline Butane & 7.6 & 17.2 & 0.7 & 7.2 & - \\
\hline 2-Methylpropene & 2.0 & 4.8 & - & 0.4 & - \\
\hline Ethanol & 1.7 & - & 2.9 & 12.8 & 1.9 \\
\hline Water & 0.2 & - & 0.3 & 0.9 & 0.2 \\
\hline ЕTВE & 54.7 & - & 93.7 & 68.8 & 96.2 \\
\hline TBA & 1.0 & - & 1.7 & 3.10 & 1.6 \\
\hline
\end{tabular}

Tab. 8. Investment $(€)$ and selected operation costs ( $€$ per year) for the simulation of ETBE production technology with the product separation by distillation.

\begin{tabular}{|c|c|c|c|c|c|}
\hline Equipment & Size & Cost/€ & Material & Amount & Cost/€ \\
\hline Mixer (MIX) & $1.4 \mathrm{~m}^{3} \mathrm{~h}^{-1}$ & 14312 & Steam & $0.99 \mathrm{GJ} \mathrm{h}^{-1}$ & 80387 \\
\hline Pump (PUMP) & $1.4 \mathrm{~m}^{3} \mathrm{~h}^{-1}$ & 2317 & Electricity & $2.25 \mathrm{~kW}$ & 1838 \\
\hline Reactor (REACTOR) & $0.25 \mathrm{~m}^{3}$ & 57900 & Cooling water & $30.8 \mathrm{~m}^{3} \mathrm{~h}^{-1}$ & 251420 \\
\hline Distilation column (RK1) & $\begin{array}{l}28 \text { stages, } \\
D=0.42 \mathrm{~m}\end{array}$ & 49952 & $\begin{array}{c}\text { Ethanol } \\
\text { C4 fraction }\end{array}$ & $\begin{array}{l}5.5 \mathrm{kmol} \mathrm{h}^{-1} \\
12 \mathrm{kmol} \mathrm{h}^{-1}\end{array}$ & $\begin{array}{l}523884 \\
628661\end{array}$ \\
\hline Distilation column (RK2) & $\begin{array}{l}12 \text { stages, } \\
D=0.15 \mathrm{~m}\end{array}$ & 20399 & Catalyst & $150 \mathrm{~kg}$ & 899 \\
\hline Equipment costs & & 144881 & \multicolumn{2}{|c|}{ Material and power media costs } & 1487089 \\
\hline Total investment capital & & 761420 & Income (ETBE) & $489 \mathrm{~kg} \mathrm{~h}^{-1}$ & 3074053 \\
\hline
\end{tabular}

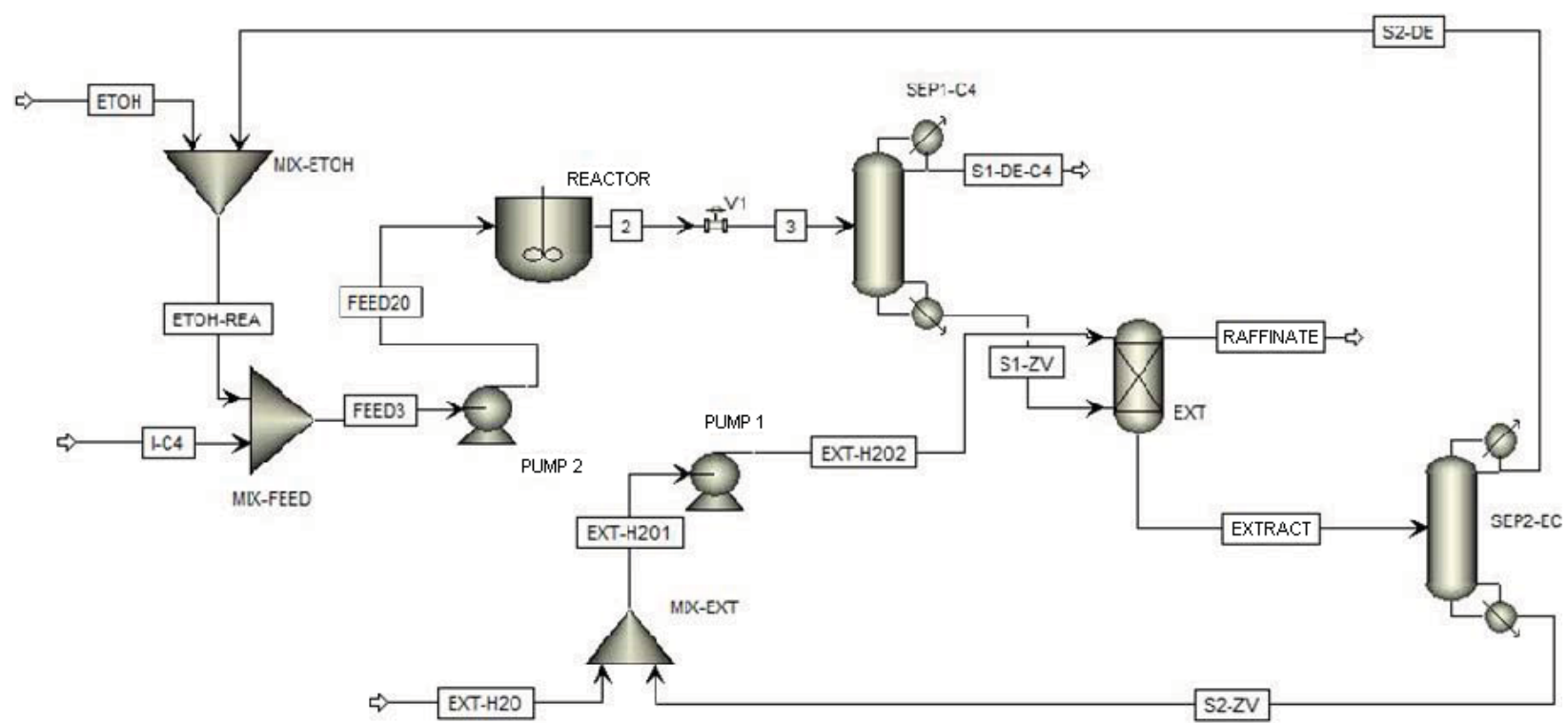

Fig. 5. Scheme of the ETBE production with the product separation by extraction. 
Tab. 9. Material flows for the simulation of ETBE production technology with the product separation by extraction.

\begin{tabular}{lccccc}
\hline Stream & $\mathbf{2}$ & S1-DE-C4 & S1-ZV & RAFFINATE & EXTRACT \\
\hline Mass flow $/\left(\mathrm{kg} \mathrm{h}^{-1}\right)$ & 992.5 & 382.5 & 610.0 & 570.4 & 670.1 \\
Temperature $/{ }^{\circ} \mathrm{C}$ & 40 & 13 & 87 & 94 & 75 \\
Pressure/ $\mathrm{MPa}$ & 0.2 & 0.2 & Content/mass \% & & 0.2 \\
\hline Component & & & - & - & - \\
\hline 1-Butene & 30.5 & 79.2 & - & - & - \\
Butane & 7.0 & 18.2 & - & - & - \\
2-Methylpropene & 1.0 & 2.6 & 7.6 & - & 6.9 \\
Ethanol & 4.7 & - & 1.4 & 7.3 & 89.2 \\
Water & 0.8 & - & 87.0 & 90.4 & 2.2 \\
ETBE & 53.5 & - & 4.0 & 2.3 & 1.7 \\
TBA & 2.5 & - & & \\
\hline
\end{tabular}

Tab. 10. Investment $(€)$ and selected operation costs ( $€$ per year) for the simulation of ETBE production technology with the product separation by extraction.

\begin{tabular}{|c|c|c|c|c|c|}
\hline Equipment & Size & Cost/€ & Material & Amount & Cost/€ \\
\hline Mixer (MIX-ETOH) & $0.5 \mathrm{~m}^{3} \mathrm{~h}^{-1}$ & 7877 & Steam & $0.75 \mathrm{GJ} / \mathrm{hod}$ & 61354 \\
\hline Mixer (MIX-FEED) & $1.5 \mathrm{~m}^{3} \mathrm{~h}^{-1}$ & 14897 & Electricity & $2.78 \mathrm{~kW}$ & 2014 \\
\hline Mixer (MIX-EXT) & $0.7 \mathrm{~m}^{3} \mathrm{~h}^{-1}$ & 9574 & Cooling water & $14.3 \mathrm{~m}^{3} \mathrm{~h}^{-1}$ & 116429 \\
\hline Reactor (REACTOR) & $0.25 \mathrm{~m}^{3}$ & 57900 & Ethanol & $5.3 \mathrm{kmol} \mathrm{h}^{-1}$ & 501380 \\
\hline Pump (PUMP 1) & $0.7 \mathrm{~m}^{3} \mathrm{~h}^{-1}$ & 3363 & C4 fraction & $12 \mathrm{kmol} \mathrm{h}^{-1}$ & 628661 \\
\hline Pump (PUMP 2) & $1.5 \mathrm{~m}^{3} \mathrm{~h}^{-1}$ & 2518 & Catalyst & $150 \mathrm{~kg}$ & 899 \\
\hline Distilation column (SEP1-C4) & $\begin{array}{l}18 \text { stages, } \\
D=0.27 \mathrm{~m}\end{array}$ & 27756 & Water for extraction & $0.04 \mathrm{~m}^{3} \mathrm{~h}^{-1}$ & 32640 \\
\hline Distilation column (SEP2-EC) & $\begin{array}{l}28 \text { stages, } \\
D=0.42 \mathrm{~m}\end{array}$ & 30314 & & & \\
\hline Extraction column (EXT) & $\begin{array}{l}8 \text { stages, } \\
D=0.3 \mathrm{~m}\end{array}$ & 6283 & & & \\
\hline Equipment costs & & 159088 & Material and pow & nedia costs & 1343377 \\
\hline
\end{tabular}

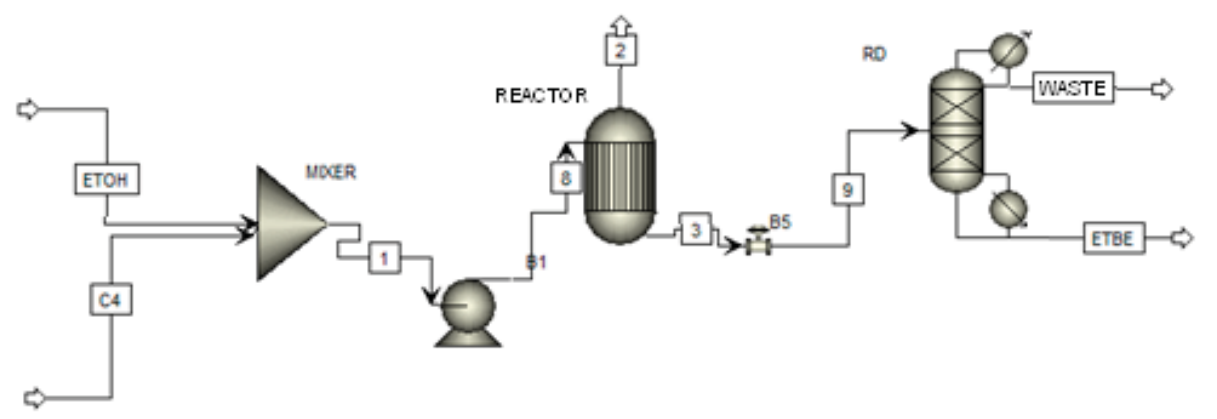

Fig. 6. Scheme of ETBE production in a straight pass reactor combined with a catalytic distillation column reactor.

ETBE production in a straight pass reactor combined with a catalytic distillation column reactor In Fig. 6, the flow chart of the ETBE production line is presented according to data by Pucci et al.
(1992) and Bakshi et al. (1992). Results of the technology simulation using Aspen + and the assessment of investment and selected operation costs are given in Tables 11 and 12, respectively. 
Tab. 11. Material flows for the simulation of ETBE production using straight pass reactor combined with reactive distillation column.

\begin{tabular}{lccc}
\hline Stream & $\mathbf{3}$ & WASTE & ETBE \\
\hline Mass flow $/\left(\mathrm{kg} \mathrm{h}^{-1}\right)$ & 931.9 & 380.0 & 553.0 \\
Temperature $/{ }^{\circ} \mathrm{C}$ & 40 & 107.1 & 210.3 \\
Pressure $/ \mathrm{MPa}$ & 2.0 & 2.0 & 2.0 \\
\hline Component & \multicolumn{3}{c}{ Content/mass \% } \\
\hline 1-Butene & 32.5 & 79.7 & - \\
Butane & 7.5 & 18.4 & - \\
2-Methylpropene & 4.7 & - & - \\
Ethanol & 4.2 & 0.6 & 0.2 \\
Water & 0.4 & - & 0.7 \\
ETBE & 50.6 & 1.2 & 99.1 \\
TBA & 32.5 & 79.7 & - \\
\hline
\end{tabular}

Comparison of the chose ETBE

production technologies

It is not that simple to evaluate and compare the three alternatives found in patent literature. Without defining the evaluation criterium/criteria it is practically impossible. A purity of the resultant product can be a criterium like this. On the other hand, one should bear in mind also the produced amount of desired product, total investment capital, yearly produced variable expenses, recoupment period, and also the technology safeness. Here, a final comparison of the chosen patent technologies for ETBE production is presented based on a combination of such criteria.

In terms of purity of the produced ETBE, the best option was the reactive separation of the unreacted reactants from the straight pass reactor. Resulting ETBE purity in this case was better than $99 \%$. On the other side, the lowest product purity was obtained when the product was separated by the liquid-phase extraction. Purity of the ETBE-rich extract stream was only about $90 \%$ that is well below the requirements on the minimum purity of ETBE used as the gasoline additive (minimum $96 \%$ purity).

In terms of the total invested capital, the largest capital investment is required, when the reactive distillation column is used to increase the reactants conversion and separate ETBE. Reactionseparation column and its measuring and control technology presents definitely the largest invest-

Tab. 12. Investment $(€)$ and selected operation costs (€ per year) for the simulation of ETBE production using straight pass reactor combined with reactive distillation column.

\begin{tabular}{lccccc}
\hline Equipment & Size & Cost/€ & Material & Amount & Cost/€ \\
\hline Mixer (MIXER) & $1.5 \mathrm{~m}^{3} \mathrm{~h}^{-1}$ & 14897 & Steam & $0.72 \mathrm{GJ} / \mathrm{hod}$ & 58399 \\
Pump (PUMP) & $1.5 \mathrm{~m}^{3} \mathrm{~h}^{-1}$ & 2284 & Electricity & $2.16 \mathrm{~kW}$ & 1763 \\
Reactor (REACTOR) & $0.25 \mathrm{~m}^{3}$ & 57900 & Cooling water & $7.8 \mathrm{~m}^{3} \mathrm{~h}^{-1}$ & 63561 \\
& & & Ethanol & $5.7 \mathrm{kmol} \mathrm{h}^{-1}$ & 542935 \\
Reactive distillation (RK1) & 28 stages, & \multirow{2}{*}{106975} & C4 fraction & $12 \mathrm{kmol} \mathrm{h}^{-1}$ & 628661 \\
& $D=0.42 \mathrm{~m}$ & & Catalyst & $500 \mathrm{~kg}^{-1}$ & 2996 \\
\hline Equipment costs & & 182057 & Material and power media costs & 1298315 \\
\hline Total investment capital & & & Income (ETBE) & $552 \mathrm{~kg} \mathrm{~h}^{-1}$ & 3470209 \\
\hline
\end{tabular}

Tab. 13. The values of FEI and IT for the equipment in different ETBE production technologies.

\begin{tabular}{|c|c|c|c|c|c|c|c|c|}
\hline \multirow{2}{*}{ Technology } & \multirow{2}{*}{ Equipment } & \multicolumn{5}{|c|}{ Parameter } & \multicolumn{2}{|c|}{ Hazard } \\
\hline & & MF & F1 & F2 & FEI & IT & Safety & Biological \\
\hline \multirow{4}{*}{ Fig. 4} & MIX & 17.2 & 2.6 & 2.1 & 92.8 & 4.6 & medium & medium \\
\hline & REACTOR & 17.2 & 3.1 & 2.1 & 110.1 & 5.2 & high & medium \\
\hline & RK 1 & 17.2 & 2.6 & 2.1 & 92.8 & 4.6 & medium & medium \\
\hline & RK 2 & 15.5 & 2.6 & 1.8 & 72.9 & 4.3 & medium & medium \\
\hline \multirow{4}{*}{ Fig. 5} & REACTOR & 16.9 & 3.1 & 2.1 & 108.6 & 5.2 & high & medium \\
\hline & SEP1 & 19.3 & 2.6 & 1.6 & 82.3 & 4.0 & medium & medium \\
\hline & SEP2 & 12.8 & 1.8 & 1.4 & 32.2 & 1.1 & low & low \\
\hline & EXT & 15.6 & 1.8 & 1.6 & 45.5 & 3.0 & low & low \\
\hline \multirow{3}{*}{ Fig. 6} & MIX & 17.1 & 2.6 & 2.1 & 92.4 & 4.6 & medium & medium \\
\hline & REACTOR & 17.2 & 3.1 & 2.1 & 110.2 & 5.2 & medium & medium \\
\hline & RD & 17.2 & 3.1 & 2.1 & 110.2 & 5.2 & high & medium \\
\hline
\end{tabular}


ment taking into account the three considered technologies. If we look for the lowest invested capital necessary for the ETBE production technology, the best choice is that with the product separation by distillation. The lowest annual costs associated with the raw material and power media consumption correspond to the reaction-separation technology of ETBE production. Comparing the lowest and highest costs of the consumed raw materials and energies, there are savings as high as $120000 €$ per year.

Revenues from the sales of ETBE produced are the highest when the technology comprising the reactive separation column is used due to the best quality and high yield of ETBE.

\section{Safety analysis}

Using the DOW method we analyzed potentially most dangerous facility included in each proposed technological scheme. Following the recommendations in Guidelines for quantitative risk assessment: Purple book (Committee for the Prevention of Disasters, 1999), the analysis consisted in choosing most likely release scenarios and events that may occur considering all the equipment of each ETBE production technology. The results of safety analysis for different technologies are given in Table 13. For pressure equipment operating at pressures exceeding atmospheric pressure by $0.1 \mathrm{MPa}$, for process equipment, in which a change of the physical properties of substances (e.g. distillation columns), and for reactors, the following events should be considered: i) immediate release of the complete content of the device (complete tear); ii) continuous leakage of the equipment content with an effective tear diameter of $0.5 \mathrm{~cm}$.

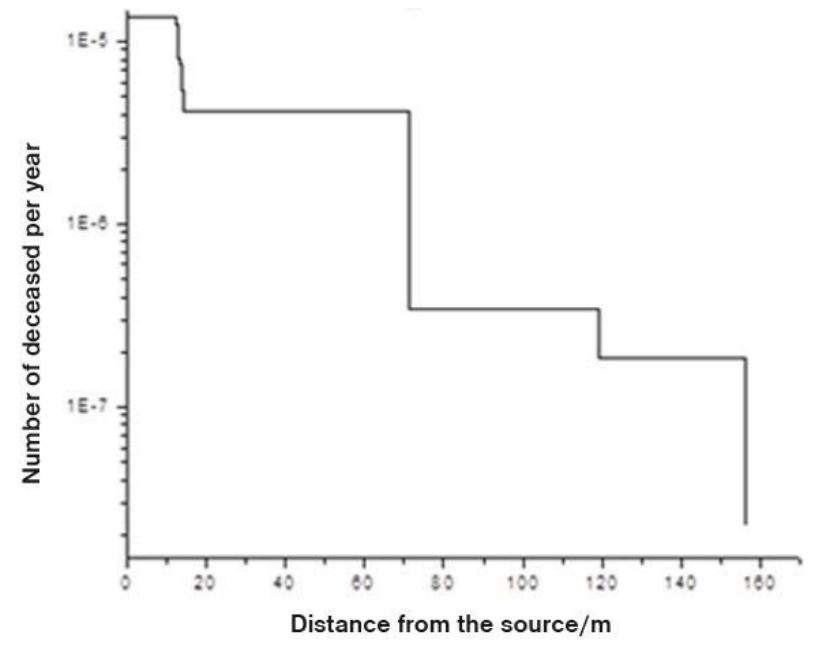

a)
In order not to underestimate the safety analysis results, also the damage of piping system should be considered. In this case, the likely scenarios (Committee for the Prevention of Disasters, 1999) are as follows: i) complete duct tear, i.e. damage of a full cross section of the discharge pipe; ii) continuous leakage from the pipe crack with a crack effective diameter of $20 \%$ of the pipe diameter.

As the graphic representation of the results of individual risk is almost the same for all the technological schemes proposed, here only the results of individual risk are presented for the ETBE production with the product separation by extraction (Fig. 7).

Social risk is the frequency of such events that caused death to more than one person at a time. Its calculation depends on the variation of population at the site and the meteorological conditions. Again, it is necessary to create a list of events that may occur and to determine the consequences that arise from such events. It is also necessary to determine the weather conditions. In this study, three possible weather conditions were considered:

i) Atmospheric stability F (very stable conditions), wind speed $1 \mathrm{~m} \mathrm{~s}^{-1}$, temperature of $25^{\circ} \mathrm{C}$, humidity $75 \%$, the average unevenness of the ground $1 \mathrm{~m}$, and probability atmosphere $20 \%$.

ii) Atmospheric stability D (neutral conditions), wind speed $2 \mathrm{~m} \mathrm{~s}^{-1}$, temperature of $20{ }^{\circ} \mathrm{C}$, humidity $75 \%$, the average unevenness of the ground $1 \mathrm{~m}$, and probability atmosphere $40 \%$.

iii) Atmospheric stability $\mathrm{C}$ (slightly unstable conditions), wind speed $4 \mathrm{~m} \mathrm{~s}^{-1}$, temperature of $20^{\circ} \mathrm{C}$, humidity $75 \%$, the average unevenness of the ground $1 \mathrm{~m}$, and probability atmosphere $40 \%$.

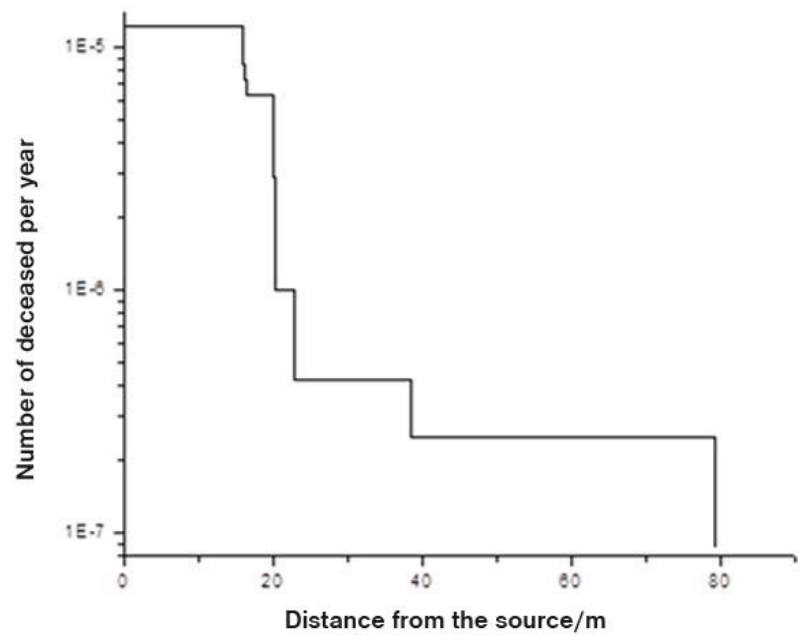

b)

Fig. 7. Individual risk calculated for distillation column (a) and reactor (b) in the ETBE production technology shown in Fig. 5. 
It is also necessary to consider the wind direction, which has an important impact on the affected area. Wind is especially important factor in the case of the toxic substances release, e.g. by causing a toxic cloud formation. If non-toxic substances leak from equipment or piping, the wind effect is not as critical, but it should also be considered. In this study the predominant directions considered were wind from N, NE, NW, E, W.

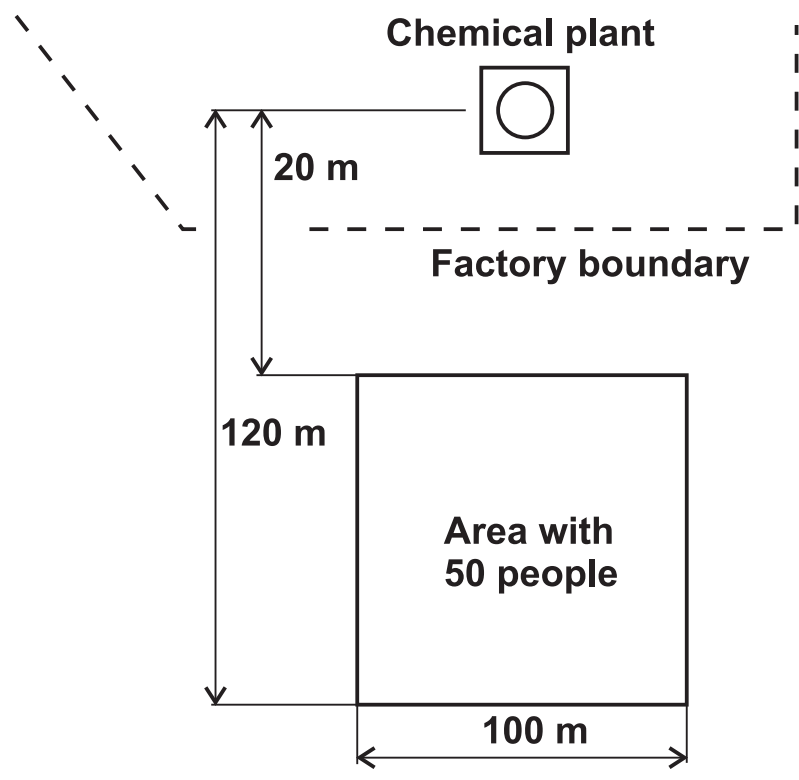

Fig. 8. Chart of the considered production plant with its surrounding.

Chart of the considered ETBE production plant and its surroundings is shown in Fig. 8. In this scenario, a space with 50 people is located only $20 \mathrm{~m}$ far from the production plant. Therefore, it is important to

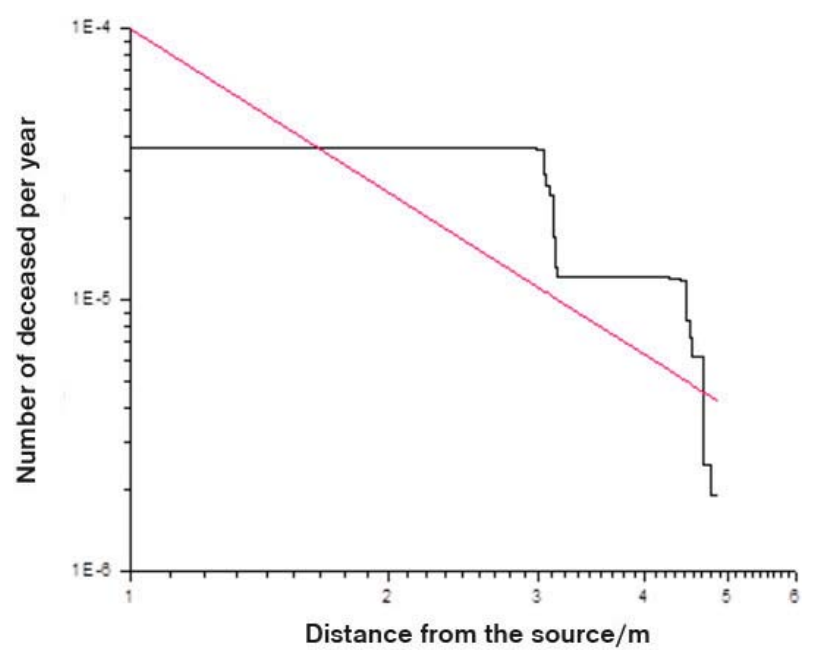

a) assess what is the risk to people in the affected zone when the plant is in service.

As the graphic representation of the results of social risk is essentially the same for all the technological scheme considered, only the results of social risks for the ETBE production technology with the product separation by extraction is presented in Fig. 9. The red line represents the curve of acceptable risk for a new plant.

The results of social risk presented in Fig. 9 show that the reactor facility and distillation column present an unacceptable risk regarding the inhabited area. Therefore, one can conclude that ETBE production plant could not be built as close to the inhabited zones. In this case study the distance of the production plant from a residential zone of $20 \mathrm{~m}$ was chosen to demonstrate the importance of the social risk evaluation. By choosing higher distance between the plant and inhabited zone, the results would not be as convincing.

In terms of safety, individual and social risks computed for all proposed ETBE production technologies are not regarded extremely dangerous. Technologies include manipulation with flammables and the safety analysis correctly identified a high degree of risk connected with the operation of reactor (exothermic reaction) and distillation column (phase changes of concentrated hydrocarbons). If the production plant is located sufficiently far from the occupied zone, it will easily meet the safety requirements set by legislation.

\section{Conclusions}

In this study, three ETBE production technologies found in patent literature were compared in terms

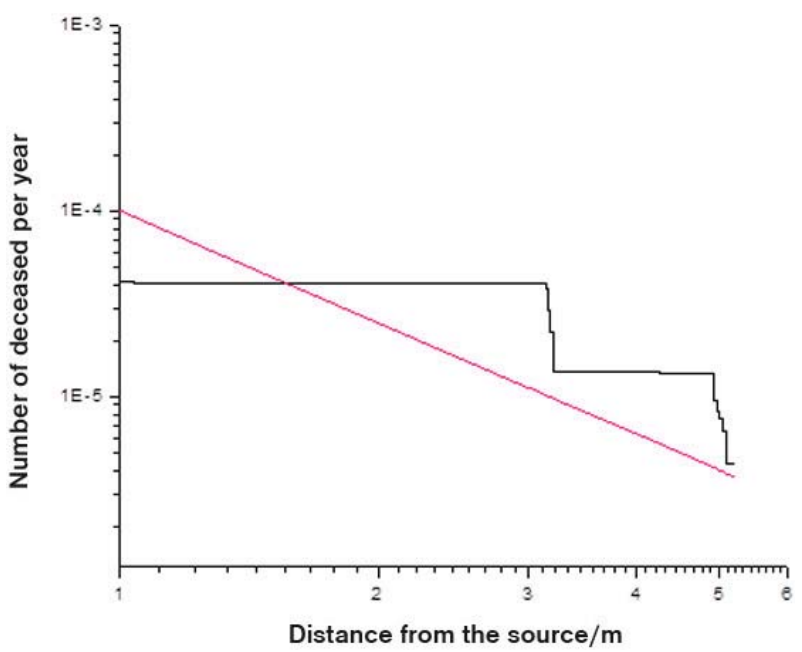

b)

Fig. 9. Computed social risk connected with the operation of reactor (a) and distillation column (b). 
of the product purity, yield, investment and selected operation costs, as well as regarding the plant operation safety. The chosen technologies basically differ in the way of product separation. The first technology combines catalytic reactor with a system of distillation columns used to separate reaction mixture components. In the second technology, the ETBE separation is carried out via liquid-phase extraction. The third technology considered profits from almost complete conversion of 2-methylpropene achieved by reactive separation.

All technologies considered were simulated using Aspen+ simulation program. Economic and safety analyses of these production schemes were carried out according to the Woods index and DOW methods, respectively. The results of simulation and economic analysis show that higher investment costs could be compensated by higher purity and yield of the product. Results of the risk assessment carried out for the three considered ETBE production technologies were essentially the same.

Based on the presented data, it could be concluded that the best alternative for ETBE production plant would be the technology that combines the reaction and separation in single equipment.

\section{Abbreviations}

\begin{tabular}{|c|c|}
\hline $\mathrm{C}_{4}$ & butanes fraction \\
\hline ETBE & $\begin{array}{l}\text { 2-ethoxy-2-methylpropane (ethyl-t-butyl } \\
\text { ether) }\end{array}$ \\
\hline $\mathrm{EtOH}$ & ethanol \\
\hline FEI & fire and explosion index \\
\hline $\mathrm{F}_{1}$ & common process factor \\
\hline $\mathrm{F}_{2}$ & special process factor \\
\hline f.o.b. & free on board \\
\hline IT & index of toxicity \\
\hline MF & material factor \\
\hline MTBE & $\begin{array}{l}\text { 2-methoxy-2-methylpropane (methyl-t- } \\
\text { butyl ether) }\end{array}$ \\
\hline NPEL & Navy’s Permissible Exposure Limit \\
\hline NRTL & $\begin{array}{l}\text { Non-Random Two-Liquid excess mo- } \\
\text { lar Gibbs energy model }\end{array}$ \\
\hline TBA & $t$-butyl alcohol \\
\hline $\mathrm{T}_{1}$ & the first toxicity index \\
\hline $\mathrm{T}_{2}$ & the second toxicity index \\
\hline UNIFAC & $\begin{array}{l}\text { UNIQUAC Functional-group Activity } \\
\text { Coefficients }\end{array}$ \\
\hline UNIQUAC & $\begin{array}{l}\text { UNIversal QUAsiChemical excess } \\
\text { molar Gibbs energy model }\end{array}$ \\
\hline
\end{tabular}

Acknowledgements

The authors kindly acknowledge partial financial support of the Slovak Research and Development Agency (grant APVV-0858-12).

\section{References}

Al-Arfaj MA, Luyben, WL (2002) Industrial \& Engineering Chemistry Research 41: 3784-3796. DOI: $10.1021 / \mathrm{ie} 010432 \mathrm{y}$.

Bakshi A, Jones EM Jr, Strain BA (1992) U.S. Patent No. 5,248,836. U.S. Patent and Trademark Office Washington, DC, USA.

Čerňanský, F. (2008) In: Bratský D (Ed.) Proceedings of the 8th International Symposium Motor Fuels 2008, June 23-26, 2008 (pp 80-91). Scientific and Technological Society at Slovnaft, plc., Tatranské Matliare, Slovak Republic. ISBN 978-80-969710-2-2.

Committee for the Prevention of Disasters (1999) Guidelines for quantitative risk assessment: Purple book. Directorate-General for Social Affairs and Employment, The Hague, The Netherlands.

EU Parliament (2003) Directive 2003/30/EC. Official Journal of the European Union L123: 42-46.

EU Parliament (2007) Regulation (EC) No 715/2007. Official Journal of the European Union L171: 1-16.

EU Parliament (2009) Directive 2009/30/EC. Official Journal of the European Union L144: 88-113.

Françoisse O, Thyrion FC (1991) Chemical Engineering and Processing: Process Intensification 30: 141-149. DOI: 10.1016/0255-2701(91)85003-7.

Jelemenský L', Labovský J, Labovská Z, Markoš J (2012) Hodnotenie nebezpečenstva chemických procesov. Nakladatel'stvo STU, Bratislava, Slovak Republic.

Kochar NK, Marcell RL (1981) U.S. Patent No. 4,334,890. U.S. Patent and Trademark Office, Washington, DC, USA.

Králik M, Macho V, Mikulec J (2000) Ropa, Uhlie, Plyn a Petrochémia 42(1): 26-29.

Mierka O (2010) Nákladové inžinierstvo, Lecture notes. Slovak University of Technology in Bratislava, Bratislava, Slovak Republic.

Mierka O (2012) Energetický audit, Lecture notes. Slovak University of Technology in Bratislava, Bratislava, Slovak Republic.

Mirzoyev V, Pushchyk Y (2009) Gasoline and its additives (MTBE, ETBE and TAME) in Europe, Russia and Ukraine. Retrieved April 7, 2013, from http://www. samoupravlenie.ru/42-12_en.php.

Nagy L (2008) In: Bratský D (Ed.) Proceedings of the 8th International Symposium Motor Fuels 2008, June 23-26, 2008 (pp 46-54). Scientific and Technological Society at Slovnaft, plc., Tatranské Matliare, Slovak Republic. ISBN 978-80-969710-2-2.

Pucci A, Mikitenko P, Zuliani M (1992) U.S. Patent No. 5,348,624. U.S. Patent and Trademark Office, Washington, DC, USA.

Seider WD, Seader JD, Lewin DR (2008) Product \& process design principles. Wiley, New York, NY, USA.

Slovak Office of Standards, Metrology and Testing (2013) STN EN 228. Slovak Office of Standards, Metrology and Testing, Bratislava, Slovak Republic.

Steltenpohl P (2011) In: Haydary J, Labovský J (Eds.) Proceedings of the Academic Conference Modern Environmental Management and Technologies organized in the framework of the Asia-Link Program of the European Commission Project Nr. 147-063, April 16-19, 2011, Kabul, Afghanistan (pp 66-83). Slovak 
University of Technology in Bratislava, Bratislava, Slovak Republic. ISBN 978-80-227-3496-7.

US EPA (1990) Clean Air Act Amendments of 1990. U.S. Environmental Protection Agency, Washington, DC, USA.

Weber de Menezes E, Cataluña R (2008) Fuel Processing Technology 89: 1148-1152. DOI: 10.1016/j.fuproc. 2008.05.006.
Yuan H (2006) ETBE as an additive in gasoline: advantages and disadvantages. Master of Science thesis, Linköpings Universitet, Norrköping, Sweden. 